Bangladesh J. Plant Taxon. 21(2): 129-137, 2014 (December)

(C) 2014 Bangladesh Association of Plant Taxonomists

\title{
POLLEN MORPHOLOGY OF THE TRIBE PHYLLODOCEAE (ERICOIDEAE, ERICACEAE) AND ITS TAXONOMIC SIGNIFICANCE ${ }^{1}$
}

\author{
A. K. M. Golam SARWAR ${ }^{2}$ and Hideki Takahashi \\ Laboratory of Systematic Botany, Graduate School of Agriculture, Hokkaido University, Japan
}

Keywords: Pollen morphology; Exine sculpture; Phyllodoceae; Taxonomic significance.

\begin{abstract}
Pollen morphology of 13 taxa belonging to 5 genera of the tribe Phyllodoceae (Ericaceae) was examined by means of light and scanning electron microscopy (LM and SEM, respectively), or SEM alone. In Phyllodoceae, 3-colpor(oid)ate, minute to medium, oblate pollen grains are united usually in tetrahedral tetrads. Pollen tetrads are generally characterized by the presence of viscin threads except Elliottia pyroliflora, Epigaea asiatica and Phyllodoce caerulea. The absence of viscin threads might indicate to a secondary loss, since these are present at least in some species within all the genera of Phyllodoceae. The pollen morphological data confirm the infra- and inter-generic relationships as identified by molecular phylogeny of Phyllodoceae and/or vice-versa. Although various palynological characters were found to be taxonomically important at different taxonomic levels, the apocolpial exine sculpture is emerged as one of the most important palynological features of systematic importance. The rugulate apocolpial exine with striate secondary sculpture and a reduced colpus might be apomorphic palynological character states for this tribe and Ericaceae as well. Hitherto, it is the first SEM study of Rhodothamnus pollen.
\end{abstract}

\section{Introduction}

The Phyllodoceae Drude is one of the most morphologically heterogeneous group that apparently has no morphological synapomorphy (Kron, 1997). Moreover, the inclusion of Epigaea in the tribe Phyllodoceae might increase the morphological heterogeneity of this group and the monophyly of this group is not well supported by morphology. Nearly all descriptions of the tribe have diagnosed the group based upon suites of characters that are homoplasious within the broader Ericoideae, rather than recognizing any particular potentially synapomorphic character (Kron et al., 2002). Gillespie and Kron (2010) used molecular data to clarify tribe-level relationships within the Ericoideae and to propose a new classification that includes five tribes, namely Rhodoreae, Empetreae, Ericeae, Bryantheae and Phyllodoceae; the Phyllodoceae is sister to a clade comprised of the other four tribes. Most members of Phyllodoceae are native to temperate-boreal regions of the Northern Hemisphere. The flowers are variable in shape, size and colour. Some species have pollen dispersed by curved stamens that spring out from the flower centre, explosively. Many species in this group are also poisonous, e.g., Kalmia, both to livestock and people. The molecular analyses indicated two strongly supported clades: Kalmia s.l. (including Leiophyllum and Loiseleuria) and a Phyllodoce clade (including Epigaea, Kalmiopsis and Rhodothamnus), and Elliottia is sister to Kalmia + Phyllodoce clade (Kron et al., 2002; Gillespie and Kron, 2013). In addition, at least one taxon from all currently recognized tribes within the Ericoideae have at some point been classified within the Phyllodoceae, illustrating the difficulty in determining relationships of these taxa based on morphological or anatomical evidence alone (Gillespie and Kron, 2013).

\footnotetext{
${ }^{1}$ A part of Ph.D. Thesis

${ }^{2}$ Present address: Department of Crop Botany, Bangladesh Agricultural University, Mymensingh 2202, Bangladesh. E-mail: drsarwar@bau.edu.bd
} 
Pollen of the family Ericaceae is very diverse - monads vs. tetrads, or as polyads of indefinite number of tetrads; and its phylogenetic importance have been well documented (Kron et al., 2002; Sarwar, 2007). Among the genera of Phyllodoceae, the pollen morphology of Kalmia has already been reported (Sarwar and Takahashi, 2012), but fragmentary palynological information is only available for other genera of this tribe (Sladkov, 1954; Oldfield, 1959; Stevens, 1971; Bohm et al., 1978; Comtois and Larouche, 1981; Clements, 1995; Kron et al., 2002; Radcliffe et al., 2010). Light microscopy (LM) was mainly employed in these studies; and scanning electron microscopy (SEM) was employed in a few cases. The aims of the present study are to provide the palynological data of the genera of Phyllodoceae in addition to Kalmia, by using both LM and SEM, and to discuss its systematic significance in light of the recent molecular phylogenetic relationship of this tribe.

\section{Materials and Methods}

Pollen morphology of 13 taxa belonging to 5 (out of 7) genera of the tribe Phyllodoceae, was examined by means of light microscopy (LM) and scanning electron microscopy (SEM), or SEM alone (Table 1). Pollen morphology of the genus Kalmia has been studied in details (Sarwar and Takahashi, 2012) and the data has been included in discussion. The remaining genus Kalmiopsis is endemic to Oregon State, USA and could not be included due to unavailability of pollen samples. Polliniferous materials used in this investigation were taken from the dried specimens of the herbaria GB, S and SAPS. Abbreviations of names of the herbaria are according to the Index Herbariorum (Holmgren et al., 1990).

Table 1. List of Phyllodoceae taxa used in this study along with their voucher specimens.

\begin{tabular}{|c|c|c|}
\hline No. & Name of the taxa & Voucher specimens \\
\hline 1. & Bejaria aestuans Mutis ex L. & $\begin{array}{l}\text { Venezuela: Edo, Tachira Hwy. 9, } 37 \mathrm{~km} \text { south of Delicias, } \\
\text { 28.01.1978, J.L. Luteyn et al. 5296 (S) }\end{array}$ \\
\hline 2. & B. racemosa Vent. & $\begin{array}{l}\text { USA: Florida, Dade Co., west of Fulford, 10.02.1930, H.N. } \\
\text { Moldenke } 601(\mathrm{~S})\end{array}$ \\
\hline 3. & B. resinosa Mutis ex L. f. & $\begin{array}{l}\text { Colombia: District Cauca, El Tambo, 08.11.1936, K. von } \\
\text { Sneidern } 1069(\mathrm{~S})\end{array}$ \\
\hline 4. & B. subsessilis Benth. & $\begin{array}{l}\text { Ecuador: Prov. Loja-Zamora road, 17.06.1979, B. Lǿjtnant \& U. } \\
\text { Molau } 15010(\mathrm{~GB})\end{array}$ \\
\hline 5. & $\begin{array}{l}\text { Elliottia bracteata (Maxim.) } \\
\text { Benth. et Hook. f. }\end{array}$ & $\begin{array}{l}\text { Japan: Hokkaido, Prov. Teshio, Masike-gun, Masike-cho, Mt. } \\
\text { Shokanbetsu, 28.07.1983, H. Takahashi } 4500 \text { (SAPS) }\end{array}$ \\
\hline 6. & $\begin{array}{l}\text { E. paniculata (Sieb. et Zucc.) } \\
\text { Benth. et Hook. f. }\end{array}$ & $\begin{array}{l}\text { Japan: Hokkaido, Hiyama-sicho, Kudoo-gun, Taisei-cho, Mt. } \\
\text { Ohta-san, 06.08.1987, H. Takahashi } 7802 \text { (SAPS) }\end{array}$ \\
\hline 7. & $\begin{array}{l}\text { E. pyroliflora (Bong.) Brim \& } \\
\text { Stevens }\end{array}$ & $\begin{array}{l}\text { USA: Alaska, Juneau Quadrangle, Mt. Roberts behind, August } \\
\text { 1967, L.A. Viereck } 8624 \text { (S) }\end{array}$ \\
\hline 8. & Epigaea asiatica Maxim. & $\begin{array}{l}\text { Japan: Hokkaido, Hiyama-shicho, Kaminokuni-cho, 18.04.1982, } \\
\text { M. Hara } 5212 \text { (SAPS) }\end{array}$ \\
\hline 9. & E. repens L. & $\begin{array}{l}\text { USA: New York, Tomplins Co., slopes on east side of valley of } \\
\text { Cayuga Intel, 13.04.1935, R.I. Clausen } 19207 \text { (S) }\end{array}$ \\
\hline 10. & $\begin{array}{l}\text { Phyllodoce aleutica (Spreng.) A. } \\
\text { Heller }\end{array}$ & $\begin{array}{l}\text { Japan: Hokkaido, Jyozankei, Mt. Yoici-dake, 02.09.1982, H. } \\
\text { Takahashi et al. } 3666 \text { (SAPS) }\end{array}$ \\
\hline 11. & P. caerulea (L.) Bab. & $\begin{array}{l}\text { Japan: Hokkaido, the Hidaka range, Mt. Poroshiri - Mt. } \\
\text { Tottabetsu, 01.08.1983, H. Takahashi } 4569 \text { (SAPS) }\end{array}$ \\
\hline 12. & $\begin{array}{l}\text { P. nipponica Makino var. } \\
\text { oblong-ovata (Tatew.) Toyokuni }\end{array}$ & $\begin{array}{l}\text { Japan: Hokkaido, Hidaka range, Mt. Poroshiri - Mt. Tottabetsu, } \\
\text { 01.08.1983, H. Takahashi } 4568 \text { (SAPS) }\end{array}$ \\
\hline 13. & $\begin{array}{l}\text { Rhodothamnus chamaecistus (L.) } \\
\text { Rchb. }\end{array}$ & Austria: Kärnten, Loibl-pass, 28.05.1960, I. Segelberg s.n. (S) \\
\hline
\end{tabular}


The preparation of pollen grains for LM and SEM, and pollen parameter studied follow Sarwar and Takahashi (2012). Pollen slides of all collection are deposited at the Hokkaido University Museum, Sapporo, Japan. Pollen size and shape classes were made following Erdtman (1986) and descriptive terminology follows Punt et al. (2007). The infrageneric classifications of Bejaria and Phyllodoce follow Clements (1995) and Good (1926 cf. Gillespie and Kron, 2013), respectively.

\section{Results and Discussion}

Pollen grains are united usually in tetrahedral tetrads, sometimes compact tetrahedral tetrads and/or with other configurations (Table 2). Viscin threads are usually present, sometime swelling at base in Bejaria aestuans, or absent in Elliottia pyroliflora, Epigaea asiatica, and Phyllodoce caerulea. The shape of the pollen grains varies from oblate to suboblate. Costae are usually distinct, but indistinct in Bejaria, 3-colpor(oid)ate (Fig. 1B), rarely 4-colporate in Rhodothamnus chamaecistus (Fig. 2K), ectoaperture (colpus) margins are distinct in all species. Endoapertures are usually distinct, but indistinct or absent in Bejaria subsessilis and Phyllodoce aleutica, lalongate, sometimes H-shaped in Epigaea repens; and endocracks are usually indistinct or absent in Phyllodoce and Rhodothamnus. Septum perforations are only observed in Phyllodoce nipponica var. oblong-ovata. The Phyllodoceae pollen ranges in mean values: D 30.0-53.3 $\mu \mathrm{m}, \mathrm{P} 15.8-26.9$ $\mu \mathrm{m}$, E 22.0-38.7 $\mu \mathrm{m}, \mathrm{D} / \mathrm{d} 1.31-1.39$, P/E 0.66-0.76, 2f 11.5-21.5 $\mu \mathrm{m}, \mathrm{W} 0.9-2.3 \mu \mathrm{m}, 2 \mathrm{f} / \mathrm{D} 0.26-$ 0.56 , endoaperture length 0.8-2.0 $\mu \mathrm{m}$, width 7.4-13.4 $\mu \mathrm{m}$, apocolpial exine 1.7-3.0 $\mu \mathrm{m}$ thick, and septum 0.9-2.8 $\mu \mathrm{m}$ thick; tectate, apocolpial exine sculpture from verrucate to rugulate (Table 2).

In SEM, apocolpial exine sculptures mainly constitute two distinct groups, viz. i) primary exine sculpture indistinct, secondary sculpture gemmate-pilate (Figs 1C, E, G-H, L) or intermediate type (Fig. 1M); ii) primary exine sculpture moderately to coarsely rugulate or rugulate-psilate or intermediate types (Figs 2B, C, D, G-I, L); colpus membrane largely granulate or granuloid.

The genera of the Phyllodoceae employed in the present study reveal variation in SEM. In Bejaria, pollen surface is somewhat flat, primary apocolpial exine sculpture indistinct, secondary sculpture finely (diam. $<0.5 \mu \mathrm{m}$ ) gemmate-pilate (Type FG; Figs 1C, E, G, H); colpus membrane largely granulate or granuloid.

In Elliottia, pollen surface is uneven to somewhat flat, primary apocolpial exine sculpture indistinct, secondary sculpture unit moderately (diam. $>0.5 \mu \mathrm{m}$ ) gemmate-pilate (Type MG; Fig. $1 \mathrm{~L})$, or intermediate type (MG/R; Fig. 1M); colpus sometimes narrow and elongate, membrane granulate. The pollen surface of Epigaea is somewhat flat, apocolpial exine sculpture coarsely rugulate, the rugulae transversely striate and intermediate type (RS/R; Fig. 2B), or coarsely rugulate-psilate and intermediate type (R/P; Fig. 2C); colpus membrane granulate. Pollen surface in Phyllodoce is uneven and rugged, apocolpial exine sculpture intermediate type (R/FG; Fig. 2G); or the surface is somewhat flat, exine sculpture moderately to coarsely rugulate (Type R; Figs 2HI); colpus membrane granulate or smooth. In Rhodothamnus, pollen surface is somewhat flat, apocolpial exine sculpture coarsely rugulate-psilate, the rugulae loosely arranged and clearly striate (Type RS; Fig. 2L); colpus membrane granuloid.

The present study reveals that in Phyllodoceae, both medium or minute and oblate pollen grains are united usually in tetrahedral tetrads (Table 2; Sarwar and Takahashi, 2012). Pollen tetrads of this tribe are generally characterized by the presence of viscin threads except in some species (Table 2; Sarwar and Takahashi, 2012). Results of the present study, in general, support previous palynological observations, however, in several instances, marked differences among the observations are apparent e.g., viscin threads on pollen tetrads of Epigaea. We did not observe any 


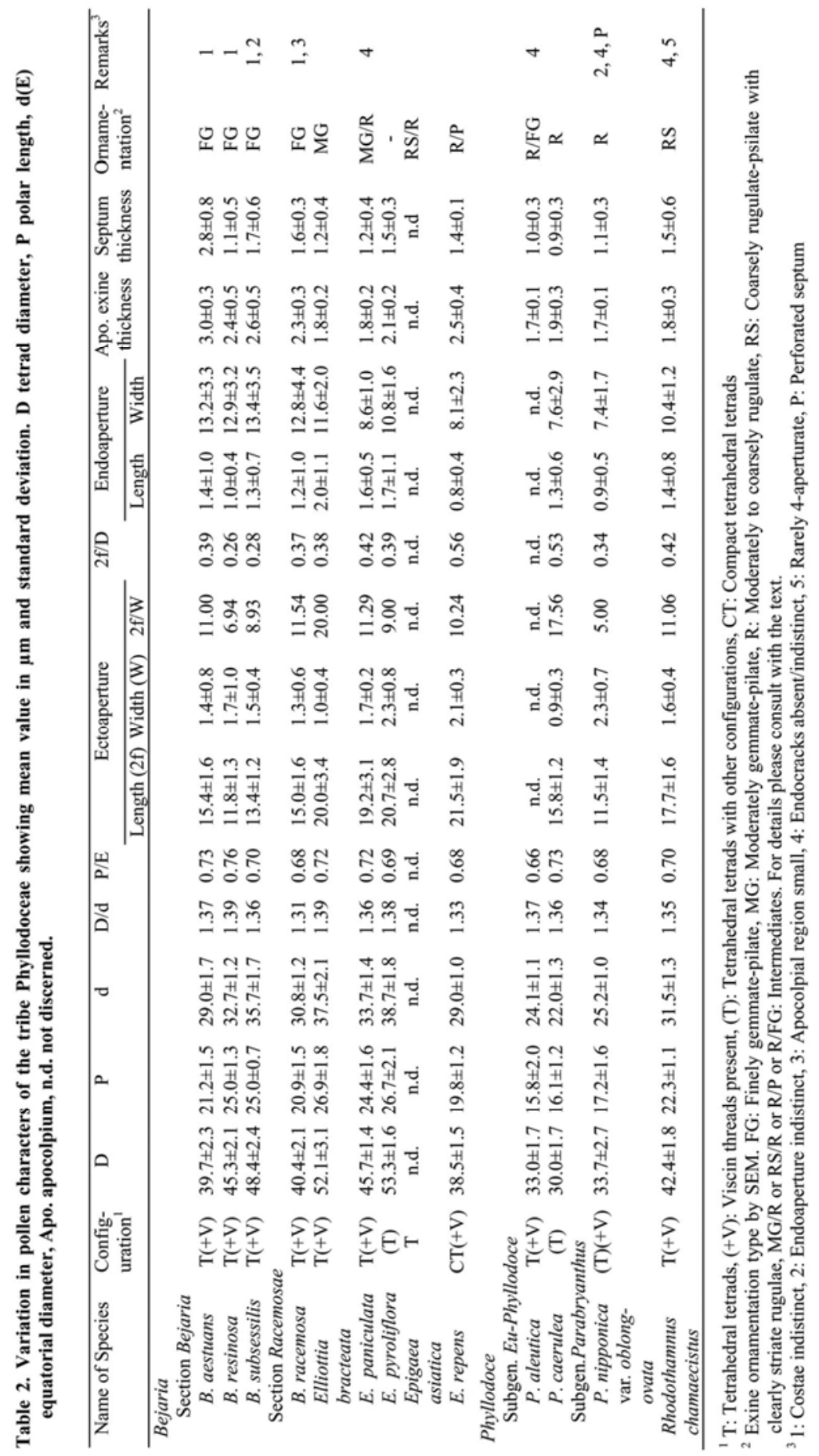



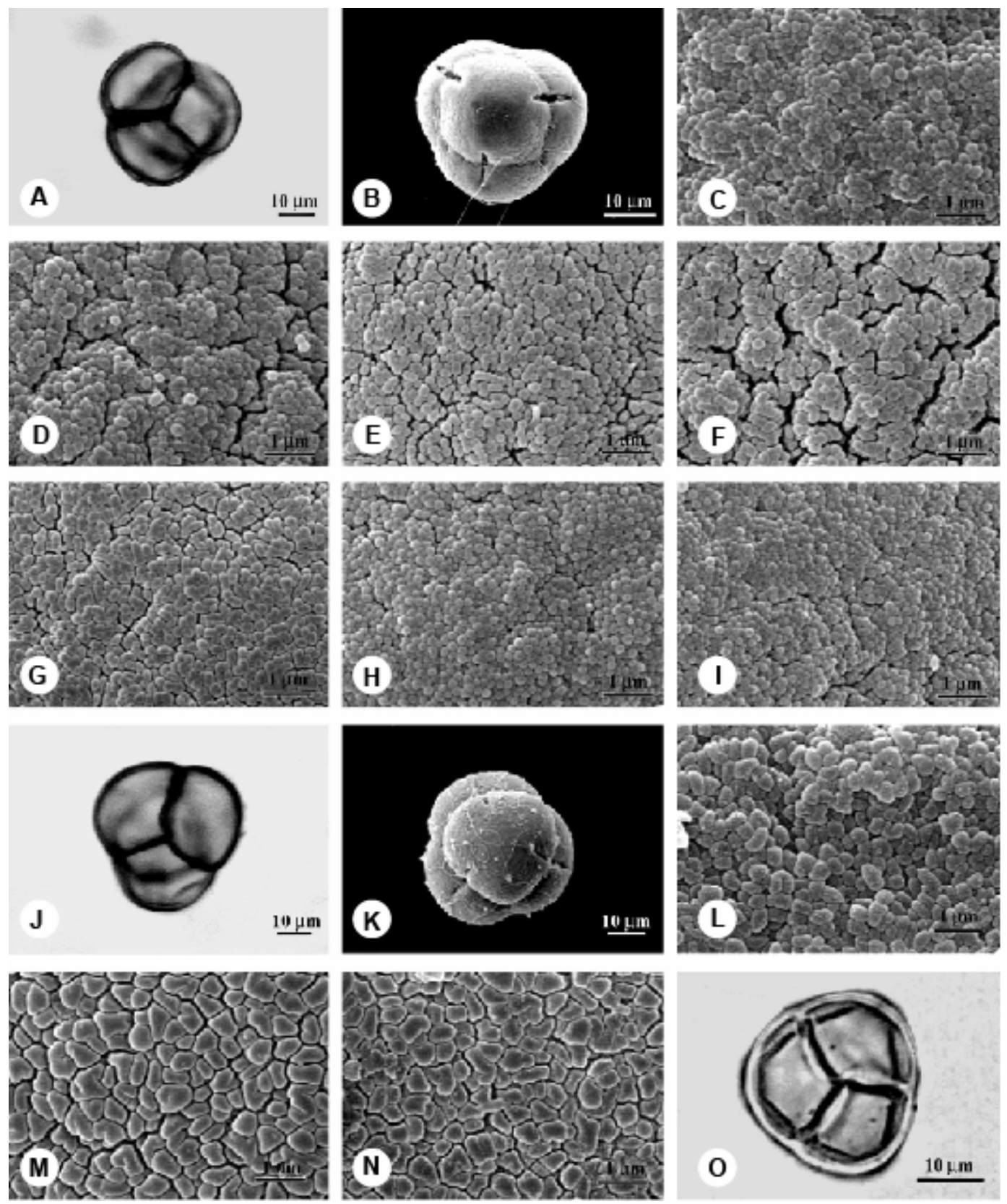

Fig. 1. LM and SEM pollen micrographs. A. Bejaria aestuans (Lutyen et al. 5296); B. B. subsessilis (Lǿjtnant \& Molau 15010); C-D. B. aestuans (Lutyen et al. 5296); E-F. B. resinosa (Sneidern 1069); G. B. subsessilis (Lǿjtnant \& Molau 15010); H-I. B. racemosa (Moldenke 601); J-K. Elliottia paniculata (Takahashi 7802); L. E. bracteata (Takahashi 4500); M-N. E. paniculata (Takahashi 7802); O. Epigaea repens (Clausen 19207). Pollen tetrads at polar view (A-B, J-K, O); pollen tetrad with viscin threads (B, $\mathrm{K}$ ); micrographs with apocolpial exine sculpture details (C, E, G, H, L, M); micrographs with mesocolpial exine sculpture details (D, F, I, N). Scale bars $=1 \mu \mathrm{m}(\mathrm{C}-\mathrm{I}, \mathrm{L}-\mathrm{N}), 10 \mu \mathrm{m}(\mathrm{A}, \mathrm{B}, \mathrm{J}, \mathrm{K}, \mathrm{O})$. 

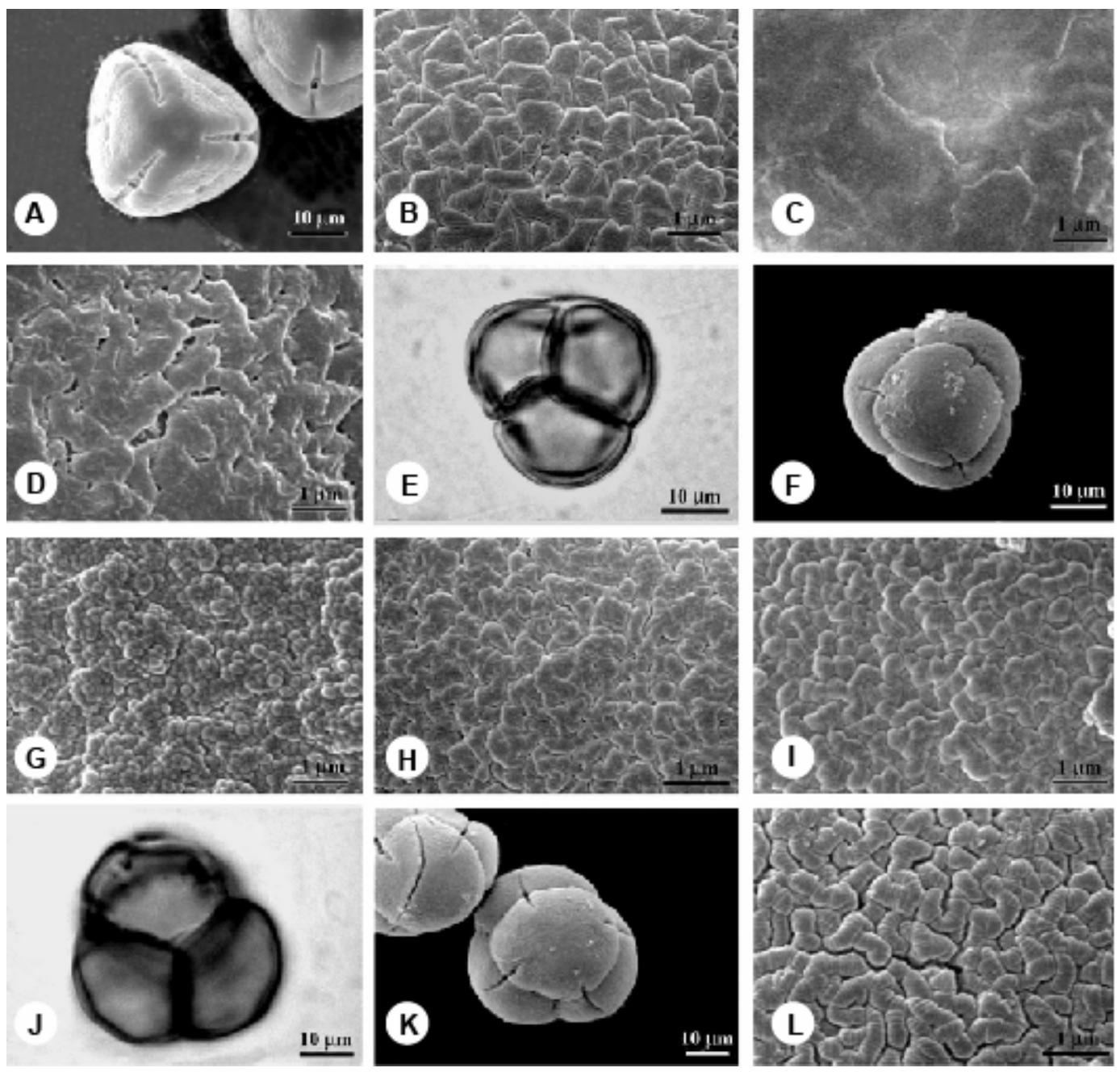

Fig. 2. LM and SEM pollen micrographs. A. Epigaea repens (Clausen 19207); B. E. asiatica (Hara 5212); C-D. E. repens (Clausen 19207); E. Phyllodoce caerulea (Takahashi 4569); F-G. P. aleutica (Takahashi et al. 3666); H. P. caerulea (Takahashi 4569); I. P. nipponica var. oblong-ovata (Takahashi 4568); J-L. Rhodothamnus chamaecistus (Segelberg s.n.). Pollen tetrads at polar view (A, E-F, J-K); tetrad with viscin threads (A, F, K); micrographs with apocolpial exine sculpture details (B-C, G-I, L); micrographs with mesocolpial exine sculpture details (D). Scale bars-1 $\mu \mathrm{m}(\mathrm{B}-\mathrm{D}, \mathrm{G}-\mathrm{I}, \mathrm{L}), 10 \mu \mathrm{m}(\mathrm{A}, \mathrm{E}$, F, J, K).

viscin threads on the pollen tetrads of E. asiatica (Table 2), although it was reported that all three species of Epigaea have viscin threads with their pollen (Stevens, 1971).

Pollen tetrads with viscin threads are often regarded as indicating to entomophilous mode of pollination in the Ericaceae (Waha, 1984; Gillespie and Kron, 2013); however, there are many entomophilous taxa in Ericaceae without viscin threads on their pollen tetrads (Buchmann, 1983). High seed-set success was reported for Phyllodoce aleutica whose pollen tetrads have viscin threads, on the other hand, co-occurring $P$. caerulea whose pollen tetrads do not have viscin threads shown the lower seed-set success (Kasagi and Kudo, 2003). The presence or absence of 
viscin threads may possibly affect the crossing and selfing ability of these two Phyllodoce species. Viscin threads might be anticipated in all species with open-campanulate inflorescence, since these are associated with insect pollination. The absence of viscin threads in P. caerulea might indicate to a secondary loss (Table 2), since viscin threads are present at least in some species within some genera of the Phyllodoceae (Gillespie and Kron, 2013).

The genera Epigaea, Rhodothamnus, Phyllodoce and Kalmiopsis, are consistently made a clade in all molecular analyses (Kron et al., 2002; Gillespie and Kron, 2010, 2013); the close relationship within these four genera also represented in their palynological features. For example, all these genera possess apocolpial exine sculptures rugulate and/or its derivatives (Table 2; Figs 2B, C, G-I, L). The exine sculpture has also been proven as a useful taxonomic tool at the infrageneric level (Sarwar and Takahashi, 2006, 2012), although various palynological characters have been found to be important at different taxonomic levels. For example, Elliottia bracteata and E. paniculata are sister taxa in all molecular analyses (Gillespie and Kron, 2013) and are characterised by the similar value $(0.72)$ of $\mathrm{P} / \mathrm{E}$ ratio (Table 2$)$.

The exine sculpture of Rhodothamnus chamaecistus, with clearly striate secondary sculpture on the rugulae (Type RS; Fig. 2L), is significantly different than that of other members of this tribe except Epigaea asiatica (RS/R; Fig. 2B), and very much similar to exine sculpture of members of the tribe Vaccinieae of subfamily Vaccinioideae (Sarwar and Takahashi, 2007). Hitherto, it is the first SEM study of Rhodothamnus pollen. In combined analyses of morphological and molecular data, Epigaea repens is strongly supported as sister to a clade of both Rhodothamnus species (Gillespie and Kron, 2013). The similarity in exine sculpture may be one of the indications of closeness of these two genera (Sarwar, 2007). The apocolpial exine with striate secondary sculpture may be an apomorphic palynological character state for this tribe, and Ericaceae as well (Kron et al., 2002; Sarwar and Takahashi, 2007).

The apocolpial exine sculpture types vary often within a single genus. For example, the exine sculptures in Epigaea asiatica and E. repens, are distinctly different (Type RS/R vs. R/P; Figs 2B, D). The other (external) morphological features of E. asiatica also differ considerably from those of E. repens (Stevens, 1969), which might be due to disjunct geographic distribution. The infrageneric variation in palynological features due to geographic distribution has also been reported for some other genera of Ericaceae e.g., Pyrola (Takahashi, 1986) and Enkianthus (Sarwar and Takahashi, 2006).

The generic circumscription of the tribe Bejarieae (Kron et al., 2002) and the systematic position of Bejaria was a matter of debate for long time (Gillespie and Kron, 2010). Based on palynological, both quantitative and qualitative features it was reported that the monotypic genus Bryanthus is clearly distinguished from other members of the tribe Bejarieae - Bejaria and Ledothamnus (Sarwar, 2007). The molecular phylogenetic studies later confirmed the above finding and transferred the genus Bejaria to the tribe Phyllodoceae and construct a new tribe Bryantheae (includes Bryanthus and Ledothamnus) (Bush and Kron, 2008; Gillespie and Kron, 2010, 2013). Between two sections, Bejaria sec. Bejaria is characterized by larger values of $\mathrm{P}$, $\mathrm{D} / \mathrm{d}, \mathrm{P} / \mathrm{E}$ and thicker apocolpial exine compared to those of Bejaria sec. Racemosae (Table 2). The close relationship between $B$. aestuans and $B$. subsessilis is supported by values of $\mathrm{D} / \mathrm{d}$, ecto- and endo-aperture length and apocolpial exine thickness (Table 2; Bush and Kron, 2008). Moreover, the monophyly of Bejaria may be supported by apocolpial exine sculpture (Table 2; Figs 1C, E, $\mathrm{G}-\mathrm{H}$ ). The pollen tetrads of Bejaria are similar to those of some Rhododendron species of the tribe Rhodoreae. But these similarities may be due to homoplasy. Indistinct costae and lower $2 \mathrm{f} / \mathrm{D}$ in Bejaria are stable and distinct palynological characters within the Ericoideae except for some species of Rhododendron and Therorhodion (Sarwar, 2007). These palynological features might imply an evolutionary tendency to a reduced (smaller) ectoaperture (Warner and Chinnappa, 
1986), and might be an apomorphic pollen character state for this genus as well as the family Ericaceae (Sarwar, 2007). Among the other genera of the tribe Phyllodoceae, the systematic significances of pollen morphological features of Kalmia have previously been discussed in details (Sarwar and Takahashi, 2012).

The pollen morphological data confirm the infra- and inter-generic relationships as identified by molecular phylogeny of Phyllodoceae (Gillespie and Kron, 2013) and/or vice-versa. Although various palynological characters were found to be taxonomically important at different taxonomic levels, the apocolpial exine sculpture is emerged as one of the most important palynological features of systematic importance. The rugulate apocolpial exine with striate secondary sculpture, and a reduced colpus might be apomorphic palynological character states for the tribe Phyllodoceae and the family Ericaceae.

\section{Acknowledgements}

We wish to express our sincere thanks to the Directors and Curators of the following herbaria: GB, S and SAPS, for allowing us to examine and/or for sending specimens on loan to sample polliniferous materials. The first author is grateful to the MEXT (Japanese Ministry of Education, Culture, Sports, Science and Technology) Scholarship during the period of this study.

\section{References}

Bohm, B.A., Brim, S.W., Hebda, R.J. and Stevens, P.F. 1978. Generic limits of the tribe Cladothamneae (Ericaceae), and its position in the Rhododendroideae. J. Arnold Arbor. 59: 311-341.

Buchmann, S.L. 1983. Buzz pollination in angiosperms. In: Jones, C.E. and Little, R.J. (Eds), Handbook of Experimental Pollination Biology. Sci. Acad. Eds., New York, pp.73-113.

Bush, C.M. and Kron, K.A. 2008. A phylogeny of Bejaria (Ericaceae: Ericoideae) based on molecular data. J. Bot. Res. Inst. Texas 2: 1193-1205.

Clements, S.E. 1995. Bejaria. In: Luteyn, J.L. (Ed.), Ericaceae - Part II: The superior-ovaried genera. Fl. Neotrop. Monogr. 66, New York Bot. Gard., Bronx, pp. 54-106.

Comtois, P. and Larouche, A. 1981. Morphologie pollinique des Éricales du Québec. Natur. Can. 108: 245262 (in French).

Erdtman, G. 1986. Pollen Morphology and Plant Taxonomy - Angiosperms. E. J. Brill, Leiden, 553 pp.

Gillespie, E.L. and Kron, K.A. 2010. Molecular phylogenetic relationships and a revised classification of the subfamily Ericoideae (Ericaceae). Mol. Phyl. Evol. 56: 343-354.

Gillespie, E.L. and Kron, K.A. 2013. Molecular phylogenetic relationships and molecular evolution within the tribe Phyllodoceae (Ericoideae, Ericaceae). Syst. Bot. 38: 752-763.

Good, R.D.O. 1926. The genera Phyllodoce and Cassiope. Le J. de Bot. 64: 1-10.

Holmgren, P.K., Holmgren, N.H. and Barnett, L.C. (Eds). 1990. Index Herbariorum, Part I: The Herbaria of the World. $8^{\text {th }}$ ed., New York Bot. Gard., Bronx, 704 pp.

Kasagi, T. and Kudo, G. 2003. Variation in bumble bee preference and pollen limitation among neighboring populations: comparisons between Phyllodoce caerulea and Phyllodoce aleutica (Ericaceae) along snowmelt gradients. Am. J. Bot. 90: 1321-1327.

Kron, K.A. 1997. Phylogenetic relationships of Rhododendroideae (Ericaceae). Am. J. Bot. 84: 973-980.

Kron, K.A., Judd, W.S., Stevens, P.F., Crayn, D.M., Anderberg, A.A., Gadek, P.A., Quinn, C.J. and Luteyn, J.L. 2002. Phylogenetic classification of Ericaceae: molecular and morphological evidence. Bot. Rev. 68: $335-423$.

Oldfield, F. 1959. The pollen morphology of some of the West European Ericales - Preliminary descriptions and a tentative key to their identification. Pollen et Spores 1: 19-48.

Punt, W., Hoen, P.P., Blackmore, S., Nilsson, S. and Le Thomas, A. 2007. Glossary of Pollen and Spore Terminology. Rev. Palaeob. Palynol. 143: 1-81. 
Radcliffe, C.A., Affolter, J.M. and Wetzstein, H.Y. 2010. Floral morphology and development in Georgia Plume, Elliottia racemosa (Ericaceae), a rare coastal plain endemic. J. Amer. Soc. Hort. Sci. 135: $487-$ 493.

Sarwar, A.K.M. Golam. 2007. Pollen morphology and its systematic significance in the Ericaceae. Ph.D. dissert., Hokkaido University, Japan. http://eprints.lib.hokudai.ac.jp/dspace/handle/2115/46925.

Sarwar, A.K.M. Golam and Takahashi, H. 2006. Pollen morphology of Enkianthus (Ericaceae) and its taxonomic significance. Grana 45: 161-174.

Sarwar, A.K.M. Golam and Takahashi, H. 2007. An overview of pollen morphology and its systematic significance within the blueberry tribe Vaccinieae (Vaccinioideae; Ericaceae). Jpn. J. Palynol. 53: 87104.

Sarwar, A.K.M. Golam and Takahashi, H. 2012. Pollen morphology of Kalmia (Phyllodoceae, Ericaceae) and its taxonomic significance. Bangladesh J. Plant Taxon. 19: 123-133.

Sladkov, A.N. 1954. Morphological description of the pollen of the Pyrolaceae, Monotropaceae, Ericaceae, Vacciniaceae and Empetraceae of the European part of USSR. Works Inst. Geo. USSR Acad. Sci. 61: 119-156 (in Russian).

Stevens, P.F. 1969. Taxonomic studies in the Ericaceae. Ph. D. Thesis, Univ. Edinburgh, UK, 678 pp.

Stevens, P.F. 1971. A classification of the Ericaceae: subfamilies and tribes. Bot. J. Linn. Soc. 64: 1-53.

Takahashi, H. 1986. Pollen morphology of Pyrola and its taxonomic significance. Bot. Mag. (Tokyo) 99: 137-154.

Waha, M. 1984. Ultrastructure and function of pollen connecting threads in Ericaceae and other Angiosperm families. Plant Syst. Evol. 147: 189-203.

Warner, B.G. and Chinnappa, C.C. 1986. Taxonomic implications and evolutionary trends in Canadian Ericales. Can. J. Bot. 64: 3113-3126.

(Manuscript received on 10 April 2014; revised on 13 November 2014) 